Seção Temática: Balanço do Fundeb Volume 10 - $2020 \mid$ n. 26

\title{
A oferta do Ensino Fundamental no contexto do FUNDEB ${ }^{1}$
}

\author{
Rosana Evangelista da Cruz \\ Universidade Federal do Piauí (UFPI), Teresina /PI - Brasil
}

Aline Kazuko Sonobe

Universidade Federal do Paraná (UFPR), Curitiba/PR - Brasil

\section{Resumo}

O artigo analisa o impacto do FUNDEB na oferta do Ensino Fundamental no Brasil, com base na evolução das matrículas, nas taxas de matrícula e atendimento escolar e na participação de estados e municípios na oferta dessa etapa de ensino, de 2007 a 2019. A metodologia do estudo envolveu revisão bibliográfica e análise documental da legislação e dos dados educacionais (INEP e IBGE). Os resultados informam que, no período em análise, houve queda de $24 \%$ nas matrículas, sendo mais acentuada no Nordeste. Apesar da referida queda, houve o crescimento dos indicadores de acesso, em que pese o não alcance da universalização do Ensino Fundamental. O FUNDEB deu continuidade ao movimento de municipalização, principalmente nos anos iniciais e nas regiões Norte e Nordeste. Nos anos finais, embora com crescimento significativo na maior parte das Unidades da Federação, a oferta manteve-se estadualizada em Roraima, Tocantins, Acre, Rondônia, Amapá, Paraná, Mato Grosso, São Paulo e Goiás.

Palavras-chave: Política Educacional. Financiamento da Educação. FUNDEB. Ensino Fundamental. Indicadores de Acesso e Participação.

\section{The offer of Fundamental Education in Fundeb's context}

\section{Abstract}

The article analyses the impact of the Fundeb in the offer of Fundamental Education in Brazil, based on the enrollment evolution, enrollment rates, and school attendance, and in the participation of states and cities in the offer of this education phase, from 2007 to 2019 . The research methodology involved a literature review and documental analysis of the legislation and education data (INEP and IBGE). The results show that in the period analyzed, there was a drop of $24 \%$ in the enrollments, being sharper in the Northeast. There was access indicators growth, despite the aforementioned drop and the non-reaching of the universalization of the Fundamental Education. The Fundeb continued the municipalization movement, mainly in the initial years and in the Northern and Northeastern regions. In the late years, although there was a significant growth in most part of the Federative Units, the offer was kept by the state in Roraima, Tocantins, Acre, Rondônia, Amapá, Paraná, Mato Grosso, São Paulo, and Goiás.

Keywords: Education Policy. Education Funding. Fundeb. Fundamental Education. Participation, and Access Indicators. 
A oferta do Ensino Fundamental no contexto do FUNDEB

\section{Introdução}

O financiamento da educação no Brasil, após os anos de 1990, foi reorganizado mediante a instituição de políticas de fundos na Educação Básica, as quais redimensionaram a forma de distribuição dos recursos vinculados à Manutenção e Desenvolvimento do Ensino (MDE), resultando na mudança do padrão de oferta das diferentes etapas e modalidades de ensino entre as redes municipais e estaduais de educação.

O Fundo de Manutenção e Desenvolvimento do Ensino Fundamental e de Valorização do Magistério (FUNDEF), criado pela Emenda Constitucional $n^{\circ} 14 / 96$ e regulamentado pela Lei $n^{\circ}$ 9.424/96, foi o pioneiro, tendo vigorado de 1996 a 2006, acentuando o processo de municipalização do Ensino Fundamental no Brasil verificado nas décadas de 1930, 1950 e 1970 (BARRETO; ARELARO, 1985). Como herdeiro do FUNDEF, foi instituído o Fundo de Manutenção e Desenvolvimento da Educação Básica e de Valorização dos Profissionais da Educação (FUNDEB), pela Emenda Constitucional $n^{\circ} 53 / 06$, regulamentada pela Lei $n^{\circ}$ 11.494/07, com vigência de 2007 a 2020, tendo, entre suas principais mudanças, a inclusão de todas as etapas e modalidades da Educação Básica, com exceção da Educação a Distância.

A Constituição Federal de 1988 (CF/1988) determinou a obrigatoriedade do Ensino Fundamental (dos 7 aos 14 anos), reconhecendo a educação como um direito social indispensável ao exercício da cidadania, portanto como um direito público subjetivo, cujo nãooferecimento ou sua oferta irregular importa responsabilidade da autoridade competente. Posteriormente, decorrente da Emenda Constitucional $n^{\circ} 59 / 2009$, houve a ampliação da obrigatoriedade para a Educação Básica dos quatro aos 17 anos de idade, incluindo a PréEscola e o Ensino Médio.

A Carta Magna de 1988 ainda determinou que a União, os estados, o Distrito Federal e os municípios organizassem, em regime de colaboração, seus sistemas de ensino, estabelecendo que estados e municípios atuassem, prioritariamente, no Ensino Fundamental (Art. 211, $\S 2^{\circ}$ e $3^{\circ}$ ). Coerente com o dispositivo constitucional, a Lei de Diretrizes e Bases da Educação Nacional (LDB $n^{\circ}$ 9.394/96) estabeleceu que todas as esferas administrativas deveriam assegurar, em primeiro lugar, o acesso ao ensino obrigatório, por isso, definiu a responsabilidade compartilhada pela sua garantia.

Aos municípios foi determinada a oferta prioritária do Ensino Fundamental, além da responsabilidade com a Educação Infantil (LDB/96, Art. 11, V). A progressiva passagem da responsabilidade do oferecimento do Ensino Fundamental (antigo $1^{\circ}$ grau) para a esfera municipal constava na Lei ${ }^{\circ} 5.692 / 1971$ (BARRETO; ARELARO, 1985), o que denota que a municipalização do ensino é perseguida há muito tempo no Brasil. Aos estados, na LDB/96, foi definida a incumbência de "assegurar o ensino fundamental e oferecer, com prioridade, 0 ensino médio" (Art. 10, VI). A União (art. 9, III) ficou com a responsabilidade de "[...] prestar assistência técnica e financeira aos Estados, ao Distrito Federal e aos Municípios para o desenvolvimento de seus sistemas de ensino e o atendimento prioritário à escolaridade obrigatória, exercendo sua função redistributiva e supletiva" (BRASIL,1996c).

A duração do Ensino Fundamental foi estabelecida, pela LDB/1996, como de, no mínimo, oito anos. No entanto, num contexto de pressão social pela efetivação do direito à educação; de recomendações internacionais para a ampliação da escolaridade obrigatória e 
A oferta do Ensino Fundamental no contexto do FUNDEB

de interesses de ordem financeiro-contábil, já no âmbito do FUNDEF (ARELARO; JACOMINI; KLEIN, 2011), essa obrigatoriedade foi redimensionada. No âmbito das estratégias de ampliação dos recursos, envolvendo, também, a inclusão das matrículas das antigas classes de alfabetização no cômputo do FUNDEF, a Lei no 11.114/2005 tornou obrigatório o início do Ensino Fundamental aos seis anos de idade. No ano seguinte, a Lei $n^{\circ} 11.274 / 2006$ alterou novamente a LDB dispondo sobre a duração de 9 (nove) anos para o Ensino Fundamental, mantendo o ingresso aos seis anos de idade e estabelecendo o prazo de implantação, pelos sistemas de ensino, até 2010. Essa ampliação estava prevista como meta na Lei $\mathrm{n}^{\circ}$ 10.172/2001, que aprovou o Plano Nacional de Educação.

As referidas mudanças têm relação direta com o movimento de reconfiguração da oferta do Ensino Fundamental, mediante processo acelerado de municipalização, induzido pelo FUNDEF. Arelaro, Jacomini e Klein (2011, p. 39) informam que "[...] a redução da idade de matrícula no Ensino Fundamental para 6 anos passou a ser gestada a partir da consolidação do processo de municipalização, quando então os municípios se conscientizaram" do alto custo desse processo, buscando, por tal estratégia, maior acesso aos recursos do referido Fundo.

Esse processo se consolidou na vigência do FUNDEF, mas assumiu características específicas no contexto do FUNDEB, porque implicou em redimensionar as prioridades no contexto de avanço da universalização do Ensino Fundamental e da inclusão das demais etapas e modalidades da Educação Básica na matriz de financiamento da educação mediante Fundos, numa conjuntura em que houve a ampliação da escolaridade obrigatória no país (BRASIL, 2009).

O fato de o FUNDEB estar em seu último ano de vigência, num contexto em que se discute sua continuidade como um Fundo permanente de financiamento da educação, são imprescindíveis avaliações que contribuam para esse processo de discussão. Frente a isso, o objetivo geral deste artigo é analisar o impacto do FUNDEB na oferta do Ensino Fundamental no Brasil. Especificamente se pretende compreender a evolução das matrículas nas regiões e Unidades da Federação, relacionando-a com a taxa de atendimento educacional e de matrícula (escolarização, segundo a nomenclatura adotada pelo IBGE) bruta e líquida, e examinar a participação de estados e municípios na oferta do Ensino Fundamental, no contexto do FUNDEB.

A metodologia do estudo envolveu análise documental e revisão bibliográfica sobre o tema. Os documentos centrais da investigação foram os dados educacionais sistematizados no Censo Escolar e a legislação que orienta a oferta do Ensino Fundamental e a política de fundos. Os dados sobre matrículas e indicadores de acesso foram coletados no Instituto Nacional de Estudos e Pesquisas Educacionais Anísio Teixeira (INEP) (1996 e 2006), no Instituto Brasileiro de Geografia e Estatística (IBGE) e no Laboratório de Dados Educacionais da Universidade Federal do Paraná (LDE/UFPR) (2007 a 2019).

A análise do impacto do FUNDEB nas matrículas do Ensino Fundamental regular das redes estaduais e municipais de ensino implicou na seleção dos dados de três anos, levando em consideração o primeiro ano do Fundo (2007), o ano mais recente com os dados consolidados (2019) e um ano intermediário (2013), visando observar a tendência na evolução das matrículas nos 13 anos de implementação. O Quadro 1 sistematiza os dados utilizados no estudo. 
Quadro 1 - Organização dos dados utilizados no estudo

\begin{tabular}{|c|c|c|c|}
\hline Indicador & Variável (Categoria) & Fonte & $\begin{array}{l}\text { Período } \\
\text { selecionado }\end{array}$ \\
\hline $\begin{array}{l}\text { Número } \\
\text { matrículas }\end{array}$ & $\begin{array}{l}\text { Etapa e modalidade de ensino } \\
\text { (Ensino Fundamental) }\end{array}$ & $\begin{array}{l}\text { Censo } \\
\text { LDE/UFPR }\end{array}$ & $\begin{array}{l}\text { 1996, 2006, 2007, } \\
2013 \text { e } 2019\end{array}$ \\
\hline População & Faixa etária (6 a 9 e 10 a 14 anos) & $\begin{array}{l}\text { Censo Demográfico, } \\
\text { PNAD/IBGE }\end{array}$ & 2000,2010 e 2018 \\
\hline $\begin{array}{l}\text { Taxa } \\
\text { atendimento } \\
\text { escolar }\end{array}$ & Faixa etária (6 a 10 e 11 a 14 anos) & LDE/ UFPR & 2007,2013 e 2015 \\
\hline $\begin{array}{ll}\text { Taxa } & \text { de } \\
\text { escolarização } & \\
\end{array}$ & $\begin{array}{l}\text { Grupos de idade - estudantes (7 a } 14 \\
\text { anos) }\end{array}$ & PNAD/IBGE & 2006 \\
\hline $\begin{array}{l}\text { Taxa de matrícula } \\
\text { bruta }\end{array}$ & $\begin{array}{l}\text { Etapa de ensino (Ensino } \\
\text { Fundamental Al e AF) }\end{array}$ & LDE/UFPR; INEP & 2007,2013 e 2015 \\
\hline $\begin{array}{l}\text { Taxa de matrícula } \\
\text { líquida }\end{array}$ & $\begin{array}{l}\text { Etapa de ensino (Ensino } \\
\text { Fundamental Al e AF) }\end{array}$ & LDE/UFPR; INEP & $\begin{array}{l}\text { 2007, 2013, } 2015 \\
\text { e } 2017\end{array}$ \\
\hline $\begin{array}{l}\text { População fora da } \\
\text { escola }\end{array}$ & Faixa etária (6 a 10 e 11 a 14 anos) & LDE/UFPR & 2007 e 2015 \\
\hline
\end{tabular}

Fonte: Elaborado pelas autoras (2020).

O presente artigo está estruturado em quatro seções, além desta introdução. A primeira apresenta, brevemente, os parâmetros das políticas de fundos. A análise da evolução das matrículas e dos indicadores de acesso e participação no Ensino Fundamental é enfrentada na segunda seção. A participação dos estados e municípios na distribuição das matrículas do Ensino Fundamental é tratada na terceira seção. As considerações finais do trabalho são apresentadas na quarta seção deste artigo.

\section{Parâmetros gerais das Políticas de Fundos}

A reorganização do sistema de financiamento da educação por meio da instituição de Fundos, inaugurada pelo FUNDEF, representou uma política educacional de caráter nacional que se destacou como política de maior impacto no sistema educacional desde a Constituição Federal de 1988, no que tange às relações federativas na oferta da educação obrigatória, motivando muitos estudos e debates que ressaltaram aspectos positivos (ABRÚCIO, 2005; PRADO, 2003; BANCO MUNDIAL, 2003) e negativos (DAVIES, 2001; PINTO, 1999; MONLEVADE, FERREIRA, 1998) dessa política para o alcance do objetivo de assegurar a universalização do atendimento ao Ensino Fundamental e a remuneração condigna do magistério.

Essa política causou mudança significativa na organização do financiamento e da oferta do Ensino Fundamental, tendo sido implementada num contexto político-econômico de reformas "[...] inspiradas em orientações dos organismos representativos do capital internacional hegemônico, em particular o Banco Mundial", indutoras de políticas de contenção de gastos sociais, que incluíram a focalização das políticas sociais em segmentos específicos da população (DAVIES, 2001, p. 15), em momento de avanço das políticas neoliberais no País.

O FUNDEF, como fundo contábil de natureza estadual, era calculado com base nos recursos a ele vinculados (15\% do Fundo de Participação dos Estados - FPE; Fundo de Participação dos Municípios - FPM; Imposto sobre Circulação de Mercadorias e Serviços ICMS; Recursos provenientes do disposto na Lei Complementar n 87/96 (BRASIL, 1996b); Imposto sobre produtos industrializados, proporcional a exportações - IPI-Exp.) e nas 
A oferta do Ensino Fundamental no contexto do FUNDEB

matrículas públicas de Ensino Fundamental de cada estado, portanto, não ocorria a migração de recursos de um estado para outro. No entanto, como sistema de cálculo e de partilha, o Fundo permitiu a migração de recursos, em função do número de matrículas, no mesmo estado, entre ele e seus municípios. O único recurso extra previsto era a complementação da União, calculada com base no valor mínimo por aluno definido nacionalmente, ou seja, encaminhado, exclusivamente, para estados que não o alcançassem.

Essa lógica, principalmente nos primeiros anos, criou grande movimentação, estimulando a competição pelas matrículas do Ensino Fundamental, sendo reconhecido que o seu maior impacto foi a municipalização dessa etapa de ensino, resultante do interesse dos gestores pelos possíveis recursos adicionais decorrentes de sua partilha (PINTO, 2007; CASTRO, DUARTE, 2007).

O formato do FUNDEF e sua natureza estadual levaram à reflexão sobre a possibilidade de essa política, de fato, servir como elemento de equalização das oportunidades educacionais previstas na legislação. No final de sua vigência, no processo de construção do FUNDEB, houve intensa participação social dos movimentos que lutaram pela instituição de um Fundo que, superando os limites do anterior, servisse como instrumento de equalização das oportunidades educacionais mediante redução das desigualdades regionais e da instituição do equilíbrio federativo (MARTINS, 2011; NASCIMENTO, 2019).

O resultado desse processo foi o FUNDEB, criado pela Emenda Constitucional n 53/06 e regulamentado pela Lei $n^{\circ} 11.494 / 07$, que preservou algumas das principais características do FUNDEF, como ser de âmbito estadual, ser composto pela maior parte dos recursos vinculados à MDE e contar com a complementação da União em situações da execução de valores por aluno ser abaixo do definido nacionalmente. No entanto, as duas mudanças mais significativas foram a ampliação de sua abrangência para todas as etapas e modalidades da Educação Básica e a definição do percentual mínimo de 10\% de complementação da União.

O FUNDEB ampliou a base de composição, passando de cinco para oito impostos e transferências constitucionais, acrescentando o Imposto sobre a Transmissão Causa Mortis e Doações (ITCMD); o Imposto Sobre Propriedade de Veículos Automotores (IPVA) e a Quota de $50 \%$ do Imposto Territorial Rural devida aos municípios (ITR). Além disso, institui um maior percentual dos recursos vinculados, que passou de $15 \%$ para $20 \%$. Ademais, manteve do Fundo anterior a determinação de que, no mínimo, $60 \%$ do total do Fundo seria para o pagamento dos profissionais da educação.

A distribuição dos recursos no FUNDEB considera diferenças entre etapas, modalidades e área da localidade do estabelecimento de ensino, com base nas matrículas apuradas no Censo Escolar do ano anterior em Creche e Pré-Escola (tempo integral e parcial); anos iniciais e finais do Ensino Fundamental (urbano, no campo e em tempo integral); Ensino Médio (urbano, no campo, em tempo integral e integrado à educação profissional); Educação Especial; Educação Indígena e Quilombola; Educação de Jovens e Adultos com avaliação no processo e a integrada à Educação Profissional de nível médio (BRASIL, 2007).

A referida distribuição dos recursos leva em conta os fatores de ponderação de cada etapa ou modalidade contemplada, estabelecidos pela Comissão Intergovernamental de Financiamento para a Educação Básica de Qualidade, e adotam como referência o fator 1 (um), anos iniciais do Ensino Fundamental urbano. No ano de implantação do FUNDEB esses fatores variavam entre 0,70 a 1,30 centésimos. 
A oferta do Ensino Fundamental no contexto do FUNDEB

Os referidos coeficientes sofreram algumas mudanças durante a vigência do FUNDEB, assim como influenciaram o padrão de oferta dos estados e municípios, embora estejam muito longe do que se almeja como referência para um padrão de qualidade, o qual só será viabilizado pela instituição do Custo-Aluno-Qualidade (CAQ), conforme aprovado no Plano Nacional de Educação $n^{\circ} 13.005 / 14$ e defendido por organizações sociais como a Campanha Nacional pelo Direito à Educação. A instituição dessa matriz demanda um modelo que corrija as desigualdades nas condições de oferta educacional mediante aumento significativo dos recursos da educação, alcançando $10 \%$ do PIB no setor, com participação mais significativa da União.

Os limites e as potencialidades do FUNDEB têm sido abordados em estudos que analisam o impacto de sua implementação nos aspectos relacionados ao atendimento (PINTO, 2012; MILITÃO, 2012; LOYOLA, 2017); ao controle social (DAVIES, 2014; BRAGA, 2015); à valorização do magistério (CAMARGO; JACOMINI, 2015; BASSI; FERNANDES; ROLIM, 2018); ao financiamento da educação (ARAÚJO, 2014; AMARAL, 2015; PINTO, 2018; ALVES; SILVEIRA; SHNEIDER, 2019; PINTO; ALVES, 2011), entre outros. Considerando que o Ensino Fundamental é a etapa da Educação Básica que concentra o maior número de matrículas públicas no Brasil, 58\% em 2019 (INEP), tendo sido a única contemplada no FUNDEF e que teve plena implantação no primeiro ano do FUNDEB, ela é tomada como foco do presente estudo. Dessa forma pretende-se contribuir com esse esforço analítico sobre o FUNDEB ao abordar a configuração do atendimento ao Ensino Fundamental, de 2007 a 2019, considerando a evolução, as taxas de atendimento e a distribuição da oferta entre as redes estaduais e municipais no Brasil, nas regiões e nas Unidades da Federação, como passamos a tratar.

\section{A evolução das matrículas no Ensino Fundamental no contexto do FUNDEB}

As matrículas do Ensino Fundamental trazem a herança do Fundo anterior, que redimensionou a oferta, como mencionado anteriormente. No aspecto relacionado à evolução do atendimento, o FUNDEF deixou como saldo o crescimento, de 1996 para 2006, de 1,4\% nas matrículas estaduais e municipais do Ensino Fundamental no Brasil. O movimento no contexto do FUNDEB será abordado a partir dos dados de 2007, 2013 e 2019 das redes estaduais e municipais de ensino. 
A oferta do Ensino Fundamental no contexto do FUNDEB

Tabela 1 - Evolução de matrículas do Ensino Fundamental estadual e municipal por região e Unidade de Federação. 2007, 2013 e 2019

\begin{tabular}{|c|c|c|c|}
\hline Região/ UF & 2007 & 2013 & 2019 \\
\hline Norte & 3.133 .256 & 2.951 .843 & 2.756 .294 \\
\hline Acre & 146.878 & 156.160 & 148.821 \\
\hline Amapá & 129.297 & 129.748 & 123.229 \\
\hline Amazonas & 738.834 & 694.741 & 649.636 \\
\hline Pará & 1.489 .237 & 1.384 .768 & 1.286 .049 \\
\hline Rondônia & 284.126 & 260.585 & 235.718 \\
\hline Roraima & 79.472 & 88.973 & 94.057 \\
\hline Tocantins & 265.412 & 236.868 & 218.784 \\
\hline Nordeste & 9.299 .869 & 7.461 .989 & 6.401 .274 \\
\hline Alagoas & 622.592 & 487.365 & 389.475 \\
\hline Bahia & 2.484 .789 & 1.949 .759 & 1.644 .587 \\
\hline Ceará & 1.411 .947 & 1.075 .483 & 930.400 \\
\hline Maranhão & 1.335 .165 & 1.174 .584 & 1.027 .077 \\
\hline Paraíba & 656.890 & 497.573 & 429.110 \\
\hline Pernambuco & 1.382 .880 & 1.110 .488 & 968.388 \\
\hline Piauí & 574.653 & 468.322 & 400.993 \\
\hline Rio Grande do Norte & 488.584 & 408.314 & 359.311 \\
\hline Sergipe & 342.369 & 290.101 & 251.933 \\
\hline Sudeste & 10.632 .129 & 9.149 .860 & 8.224 .535 \\
\hline Espírito Santo & 495.307 & 460.408 & 438.740 \\
\hline Minas Gerais & 3.004 .456 & 2.473 .971 & 2.137 .824 \\
\hline Rio de Janeiro & 1.925 .332 & 1.579 .492 & 1.355 .716 \\
\hline São Paulo & 5.207 .034 & 4.635 .989 & 4.292 .255 \\
\hline Sul & 3.901 .862 & 3.327 .703 & 3.052 .003 \\
\hline Paraná & 1.548 .364 & 1.331 .046 & 1.194 .275 \\
\hline Rio Grande do Sul & 1.501 .994 & 1.270 .612 & 1.107 .168 \\
\hline Santa Catarina & 851.504 & 726.045 & 750.560 \\
\hline Centro-Oeste & 2.033 .425 & 1.820 .321 & 1.749 .416 \\
\hline Distrito Federal & 312.732 & 297.958 & 274.164 \\
\hline Goiás & 841.850 & 733.227 & 707.167 \\
\hline Mato Grosso & 492.003 & 424.170 & 419.805 \\
\hline Mato Grosso do Sul & 386.840 & 364.966 & 348.280 \\
\hline Brasil & 29.000 .541 & 24.711 .716 & 22.183 .522 \\
\hline
\end{tabular}

Fonte: INEP. LDE/UFPR.

Se no FUNDEF houve pequeno crescimento nas matrículas estaduais e municipais do Ensino Fundamental no Brasil, no contexto do FUNDEB, de 2007 para 2019, houve queda de $24 \%$, ou seja, a diminuição de quase um quarto do total de matrículas. A queda ocorreu em todas as regiões do País, mas foi mais intensa no Nordeste $(31 \%)$, no Sudeste $(23 \%)$ e no Sul $(22 \%)$.

No que tange às Unidades da Federação, de 2007 para 2019, o aumento de matrículas foi observado apenas em Roraima (18\%) e Acre (1\%). Por outro lado, as quedas foram mais significativas, em todo o período analisado, principalmente nos estados nordestinos que recebem a complementação da União do FUNDEB: Alagoas (37\%), Paraíba (25\%), Ceará (34\%), Bahia (33\%), Piauí (30\%) e Pernambuco (30\%). Não obstante, queda expressiva das 
A oferta do Ensino Fundamental no contexto do FUNDEB

matrículas do Ensino Fundamental também foi observada no Rio de Janeiro (30\%) e Minas Gerais (29\%), Rio Grande do Norte (27\%), Sergipe (26\%) e Rio Grande do Sul (26\%).

$\mathrm{Na}$ busca dos motivos para queda tão acentuada nas matrículas do Ensino Fundamental, foram sistematizadas informações sobre a taxa de atendimento escolar (de escolarização, como denomina o IBGE) e de matrícula bruta e líquida, visando problematizar se a queda estaria relacionada ao processo de universalização do atendimento, portanto a uma saturação na oferta do Ensino Fundamental.

A taxa de atendimento escolar é um indicador que mostra o percentual de crianças e adolescentes que se encontram matriculados na creche ou na escola, tendo como referência o Dia Nacional do Censo Escolar (na última $4^{a}$ feira do mês de março), visando identificar possíveis carências de acesso. No Brasil se observa um aumento constante da taxa de atendimento escolar da população de seis a 10 anos, passando de $97,8 \%$ para $99,2 \%$, de 2007 para 2015.

No mesmo recorte temporal, aumentou de $96 \%$ para $97,7 \%$ da população de 11 a 14 anos, apesar do número de matrículas do Ensino Fundamental ter apresentado queda significativa, como tratado anteriormente. Independentemente das regiões, a taxa de atendimento de 11 a 14 anos é menor em relação à taxa de 6 a 10 anos, isto é, há menos crianças e adolescentes daquela faixa de idade frequentando a escola. As menores taxas de atendimento estão presentes nas regiões Norte e Nordeste, tanto nos anos iniciais quanto nos anos finais do Ensino Fundamental. Embora possa ser visto com otimismo o crescimento das taxas, os dados do IBGE revelam que, em 2015, havia 122.295 crianças de 6 a 10 anos fora da escola, assim como 307.306 de 11 a 14 anos, denunciando a emergência de políticas que incluam essa população no sistema visando viabilizar seu direito à educação. Não há justificativa, nesse sentido, para a queda nas matrículas do Ensino Fundamental.

A taxa de matrícula bruta possibilita comparar o total de matrículas do Ensino Fundamental com a população na faixa etária considerada adequada, portanto, dos seis aos 14 anos. O cálculo envolve a informação do Censo Escolar (INEP) e as informações populacionais da Pesquisa Nacional por Amostra de Domicílios (PNAD/IBGE), por grupo etário. Nesse caso, a taxa pode assumir valores superiores a $100 \%$, já que o total de matrícula pode ser superior à população na faixa etária relacionada.

No Brasil, em 2007, a taxa de matrícula bruta dos anos iniciais foi de 103,3\% e, dos anos finais, $100,1 \%$, tendo alcançado $105 \%$ e $94,7 \%$, em 2015, respectivamente. Em 2007 , Norte e Nordeste apresentavam as maiores taxas brutas entre as regiões, $114 \%$ e $110 \%$, respectivamente. Em 2015, houve diminuição nas duas regiões, principalmente no Nordeste, que alcançou 102\%. No entanto, ocorreu crescimento nas demais regiões, de 2007 para 2015, especialmente no Sul (de 98\% para 108\%) e no Sudeste (de 98\% para 105\%). Esses dados informam que o movimento de ampliação ou diminuição do número de matrículas tem relação com a distorção idade-série.

O comportamento da taxa bruta dos anos finais do Ensino Fundamental é marcado pela inversão em relação aos anos iniciais, porque essas taxas, em 2007, foram maiores nas regiões mais desenvolvidas economicamente: Centro-Oeste (108\%), Sul (103\%), Sudeste $(102 \%)$, situação que se manteve em 2015 , embora tenha ocorrido queda para $96 \%, 99 \%$ e $98 \%$, respectivamente. 
Por último, apresenta-se a taxa de matrícula líquida, que identifica o percentual da população matriculada no nível de ensino na faixa etária esperada. O diagnóstico do PNE/2001 explicitou que, em 1996, existiam mais de 35 milhões de matrículas no Ensino Fundamental, número que representava $116 \%$ do total de crianças de 7 a 14 anos, o que revelava que quase 9 milhões de matrículas eram de pessoas com menos de 7 anos ou com mais de 14 anos de idade (BRASIL, 2001), resultando na taxa de escolarização líquida de $90,8 \%$. No ano de 2006 , esse índice era de $94,8 \%$ (IBGE), sendo a taxa de escolarização bruta de $97,6 \%$ (calculada para a população de 7 a 14 anos).

No contexto do FUNDEB, a Meta 2 do PNE, que estabelece universalizar o Ensino Fundamental de nove anos para toda a população de seis a 14 anos e garantir que pelo menos 95\% dos alunos concluam essa etapa na idade recomendada, até o último ano de vigência (BRASIL, 2014), está relacionada com esse indicador. Os Relatórios do Segundo e Terceiro Ciclo do PNE (INEP, 2018; 2020) explicitam que o percentual da população de seis a 14 anos que frequentava ou que já havia concluído o Ensino Fundamental em 2007 era de 93,7\% (INEP, 2018), tendo alcançado, em 2019, 98,1\%, portanto, cumprindo a Meta do Plano (INEP, 2020). Por região, em 2019, a maior taxa era no Sul $(98,3 \%)$ e as menores no Norte $(97,4 \%)$ e Nordeste (97,9\%). Apesar da menor taxa nessas regiões, o Relatório informa seu crescimento, de 2013 para 2019, em todas as regiões, principalmente no Norte e Nordeste do País (INEP, 2020).

A taxa de escolarização líquida no Ensino Fundamental (anos iniciais e finais), em 2007, 2013 e 2015, apresenta-se a seguir.

Gráfico 1 - Taxa de Escolarização Líquida nos anos iniciais e finais do Ensino Fundamental. Regiões. 2007, 2013, 2015

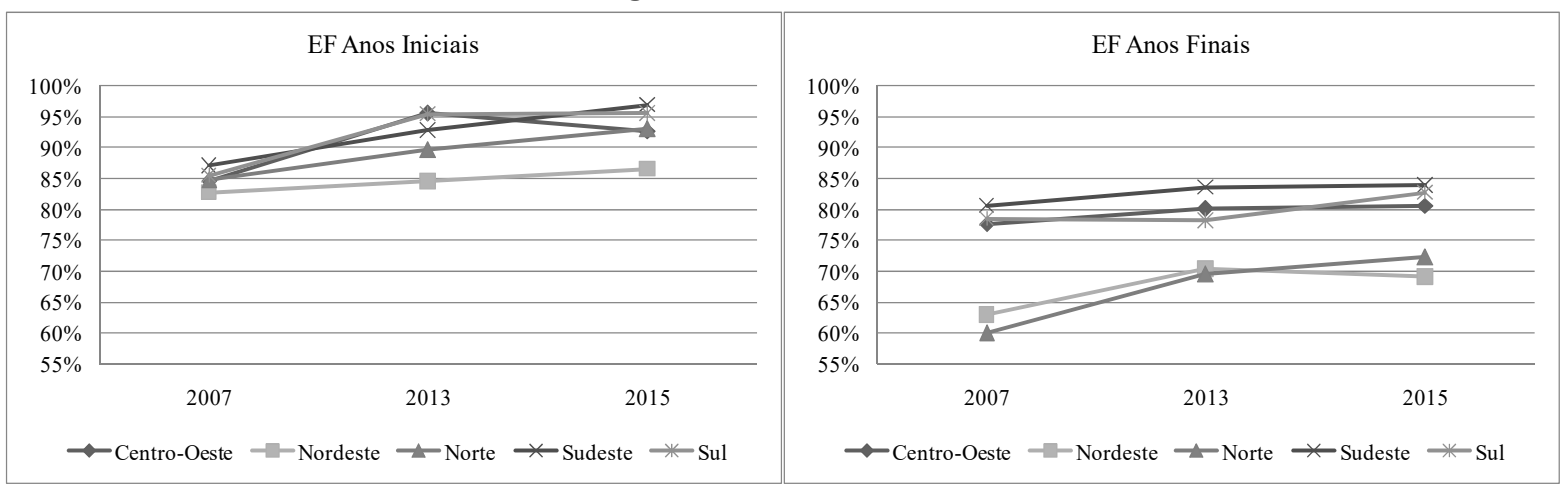

Fonte: Elaborada pelas autoras com base nos dados do IBGE sistematizados pelo LDE/UFPR.

A análise desagregada por etapa do Ensino Fundamental revela que, no que tange aos anos iniciais, houve crescimento constante da taxa de escolarização líquida, exceto no Centro-Oeste, de 2013 para 2015, porque houve queda de $95,5 \%$ para $92,7 \%$. O maior crescimento, de 2007 para 2015, ocorreu nas regiões Sul e Sudeste (10\%). O menor, na região Nordeste (4\%), justamente a região mais longe do alcance da meta do PNE $(86,5 \%)$.

No que tange aos anos finais do Ensino Fundamental, houve crescimento constante da taxa de escolarização líquida, exceto no Nordeste, de 2013 para 2015, decorrente da queda de $70,4 \%$ para $69,1 \%$. Nessa etapa do Ensino Fundamental a taxa de escolarização líquida está mais longe da Meta 2 do PNE, principalmente no Nordeste $(69,1 \%)$ e o Norte $(72,3 \%)$. Não obstante essa condição, observa-se um movimento crescente da taxa, de 2007 para 2015 , com aumento de $12 \%$ e $6 \%$, respectivamente. 
A questão que se coloca é: como pode estar ocorrendo o crescimento das taxas de atendimento se, efetivamente, houve queda de $24 \%$ no número de matrículas no Ensino Fundamental no Brasil de 2007 para 2019? A resposta foi procurada na pirâmide etária da população. Segundo o IBGE, pessoas com 5 a 14 anos de idade totalizavam 33.890.394 (corresponde a $20 \%$ da população) em 2000, já em 2010, esse número passou para 32.136 .136 (corresponde a $17 \%$ da população), indicando uma redução de $5 \%$. Seguindo esse movimento, em 2018, a população na faixa etária de 6 a 14 anos totalizava 25.970.000, correspondendo a $13 \%$ do povo brasileiro (IBGE). A tendência de envelhecimento da população e de redução da taxa de natalidade pode explicar, em parte, o aumento das taxas de atendimento e de matrícula bruta e líquida, apesar da queda no número de matrículas do Ensino Fundamental, que também se explica pelos processos de correção da distorção sérieidade.

A resposta para esse problema também foi buscada na análise da evolução e da distribuição do número de matrículas por etapa e modalidade da Educação Básica segundo dependência administrativa, visando compreender a recomposição da oferta, decorrente da significativa redução das matrículas, como tratado anteriormente.

Tabela 2 - Distribuição de matrículas por etapa e modalidade da Educação Básica por dependência administrativa. 2007 e 2019

\begin{tabular}{|c|c|c|c|c|c|c|}
\hline \multirow{2}{*}{ Etapa/Modalidade } & \multicolumn{3}{|c|}{2007} & \multicolumn{3}{|c|}{2019} \\
\hline & Total $(\mathrm{N})$ & Estadual & Municipal & Total (N) & Estadual & Municipal \\
\hline Creche & 1.052 .649 & 1,0 & 99,0 & 2.455 .405 & 0,2 & 99,8 \\
\hline Pré-Escola & 3.912 .055 & 4,5 & 95,5 & 4.008 .839 & 1,4 & 98,6 \\
\hline Ensino Fundamental (Al) & 16.068 .572 & 24,1 & 75,9 & 12.132 .073 & 16,3 & 83,7 \\
\hline Ensino Fundamental (AF) & 12.931 .969 & 58,0 & 42,0 & 10.051 .449 & 49,2 & 50,8 \\
\hline Ensino Médio ${ }^{1}$ & 7.403 .994 & 97,8 & 2,2 & 6.307 .385 & 99,4 & 0,6 \\
\hline $\mathrm{EJA}^{2}$ & 4.849 .286 & 60,0 & 40,0 & 3.049 .102 & 57,2 & 42,8 \\
\hline Educação Profissional ${ }^{3}$ & 239.786 & 90,0 & 10,0 & 330.401 & 95,3 & 4,7 \\
\hline Total & 46.458 .311 & 47,2 & 52,8 & 38.334 .654 & 39,9 & 60,1 \\
\hline
\end{tabular}

Nota:

1 Soma de matrículas do Ensino Médio com Ensino Profissional Integrado ao Médio Integrado ou Normal - técnico

2 Soma de matrículas da Educação de Jovens e Adultos - Ensino Fundamental, Ensino Médio e EJA - EF e EM Integrado técnico

${ }^{3}$ Concomitante e subsequente

Fonte: Elaborada pelas autoras com base em INEP e LDE/UFPR, 2007 e 2019.

A abordagem sobre a distribuição das matrículas entre as etapas de ensino será precedida de algumas considerações sobre a evolução daquelas que não compõem o Ensino Fundamental, com o intuito de ponderar se a queda de $24 \%$ nessa etapa de ensino decorreu da ampliação nas demais etapas da Educação Básica. Os dados do INEP, expostos na Tabela 2, informam que a única etapa de ensino incluída no FUNDEB que teve crescimento, de 2007 para 2019 , foi a Educação Infantil, $133 \%$ na creche e $2 \%$ pré-escola. Ainda houve aumento na Educação Profissional concomitante ou subsequente ao Ensino Médio (38\%), que não participa da matriz do Fundo. O Ensino Médio, incluindo a Educação Profissional dessa etapa, e a EJA também tiveram diminuição no atendimento, 15\% e 37\%, respectivamente. Portanto, - FUNDEB impactou positivamente somente nas matrículas da Educação Infantil, de competência dos municípios. 
A oferta do Ensino Fundamental no contexto do FUNDEB

A prevalência do atendimento público na Educação Básica municipal está colocada desde o primeiro ano do FUNDEB (52,8\%), alcançando 60\% em 2019. A Educação Infantil se destaca nessa rede, conforme determinação legal, se expressando no contexto do FUNDEB com $99 \%$ das matrículas. As redes estaduais, desde 2007, concentram quase a totalidade das matrículas no Ensino Médio $(97,8 \%)$, aqui considerando, também, as integradas à Educação Profissional, alcançando $99,4 \%$ em 2019. A oferta estadual também foi preponderante, em 2007, na EJA (60\%) e na Educação Profissional concomitante ou subsequente ao Ensino Médio (90\%), havendo pequena queda na participação percentual em EJA $(57,2 \%)$ e crescimento na Educação Profissional não integrada $(95,3 \%)$.

Os 13 anos de vigência do FUNDEB também resultaram em mudanças importantes na distribuição das matrículas entre as redes de ensino, assunto da próxima seção deste artigo.

\section{Participação das diferentes dependências administrativas na oferta do Ensino Fundamental}

O debate sobre municipalização do ensino no Brasil tem implicado discussões que envolvem aspectos relacionadas à descentralização, à participação e à autonomia dos entes federados. No âmbito deste artigo, a municipalização será tratada no aspecto relacionado às atribuições com a oferta educacional assumida pelos municípios com a instituição da política de fundos. Por meio da análise da distribuição de matrículas por dependência administrativa, buscou-se responder a seguinte questão: a tendência de municipalização do Ensino Fundamental, constatada durante a vigência do FUNDEF (1996-2006), permaneceu durante o FUNDEB (2007-2019)?

Para tanto, a análise da participação das diferentes dependências administrativas na oferta do Ensino Fundamental terá como referência o percentual de municipalização calculado pela seguinte fórmula:

$$
\% \text { municipalização }=\frac{\text { matrículamunicipal }}{\sum \text { matrículaestadual,matrículamunicipal }}
$$

A aplicação dessa fórmula nas matrículas do Ensino Fundamental contribuiu para análise da tendência de municipalização dos anos iniciais e finais por região e Unidade Federativa, tomando como referência os anos de 2007, 2013 e 2019. O ano de 2013 foi adotado para verificar se houve mudança de rota na distribuição do atendimento, entre o primeiro e o último ano analisado. 
Tabela 3 - Percentual de municipalização no Ensino Fundamental (anos iniciais e finais) por Unidade Federativa e por Região. 2007, 2013 e 2019

\begin{tabular}{|c|c|c|c|c|c|c|}
\hline \multirow{2}{*}{ Região/ UF } & \multicolumn{2}{|c|}{2007} & \multicolumn{2}{|c|}{2013} & \multicolumn{2}{|c|}{2019} \\
\hline & EFAI & EFAF & EFAI & EFAF & EFAI & EFAF \\
\hline Norte & 73,8 & 44,5 & 79,6 & 49,4 & 84,8 & 52,1 \\
\hline Acre & 48,2 & 18,1 & 54,3 & 16,6 & 57,2 & 14,0 \\
\hline Amapá & 39,3 & 10,2 & 57,2 & 7,1 & 65,3 & 6,2 \\
\hline Amazonas & 73,0 & 39,5 & 76,1 & 42,7 & 77,6 & 50,3 \\
\hline Pará & 85,7 & 61,7 & 91,1 & 72,2 & 92,8 & 76,9 \\
\hline Rondônia & 61,1 & 33,0 & 64,3 & 29,7 & 84,6 & 15,3 \\
\hline Roraima & 37,8 & 6,2 & 75,2 & 4,7 & 84,9 & 4,1 \\
\hline Tocantins & 60,7 & 26,4 & 66,3 & 27,6 & 90,2 & 28,5 \\
\hline Nordeste & 88,3 & 62,7 & 94,5 & 72,2 & 96,7 & 81,2 \\
\hline Alagoas & 87,3 & 66,7 & 94,0 & 72,4 & 95,6 & 77,1 \\
\hline Bahia & 93,3 & 62,9 & 98,8 & 71,2 & 99,7 & 82,3 \\
\hline Ceará & 97,7 & 76,8 & 99,1 & 87,8 & 99,3 & 96,6 \\
\hline Maranhão & 91,1 & 71,2 & 96,1 & 89,8 & 98,7 & 95,2 \\
\hline Paraíba & 74,4 & 52,5 & 80,7 & 58,1 & 90,6 & 66,3 \\
\hline Pernambuco & 86,6 & 46,0 & 96,3 & 54,3 & 98,4 & 68,3 \\
\hline Piauí & 82,0 & 71,7 & 96,6 & 74,4 & 99,1 & 81,1 \\
\hline Rio Grande do Norte & 73,1 & 54,8 & 78,8 & 58,5 & 82,8 & 65,2 \\
\hline Sergipe & 72,6 & 51,0 & 78,3 & 57,3 & 80,7 & 62,0 \\
\hline Sudeste & 68,6 & 32,8 & 76,2 & 35,8 & 77,6 & 38,3 \\
\hline Espírito Santo & 80,0 & 62,7 & 83,0 & 63,7 & 87,5 & 61,1 \\
\hline Minas Gerais & 62,1 & 29,3 & 66,3 & 30,9 & 69,5 & 31,1 \\
\hline Rio de Janeiro & 87,0 & 58,3 & 98,6 & 64,7 & 99,8 & 73,6 \\
\hline São Paulo & 64,0 & 23,6 & 72,8 & 26,5 & 73,6 & 28,4 \\
\hline Sul & 73,1 & 26,3 & 76,7 & 29,3 & 79,6 & 31,1 \\
\hline Paraná & 96,6 & 3,1 & 99,5 & 2,6 & 99,5 & 1,5 \\
\hline Rio Grande do Sul & 55,8 & 43,7 & 58,3 & 47,9 & 63,0 & 51,3 \\
\hline Santa Catarina & 62,0 & 39,3 & 68,9 & 48,1 & 72,4 & 48,0 \\
\hline Centro-Oeste & 62,2 & 29,8 & 67,9 & 30,6 & 71,8 & 27,6 \\
\hline Distrito Federal ${ }^{1}$ & - & - & - & - & - & - \\
\hline Goiás & 82,2 & 28,8 & 92,2 & 33,7 & 96,5 & 29,0 \\
\hline Mato Grosso & 64,3 & 37,8 & 67,6 & 32,9 & 70,3 & 28,8 \\
\hline Mato Grosso do Sul & 69,8 & 45,8 & 73,0 & 48,0 & 80,3 & 45,7 \\
\hline Brasil & 75,9 & 42,0 & 81,6 & 46,9 & 83,7 & 50,8 \\
\hline
\end{tabular}

Nota: ${ }^{1}$ Não é possível o cálculo da municipalização no Distrito Federal porque todas as matrículas são de responsabilidade do governo distrital.

Fonte: Elaborada pelas autoras com base em INEP e LDE/UFPR, 2007, 2013 e 2019.

A Tabela 3 informa o avanço na tendência de municipalização, que é mais acentuada nos anos iniciais do Ensino Fundamental, pois sai de 75,9\%, em 2007, e alcança $83,7 \%$, em 2019. No mesmo período, os anos finais saem dos $42 \%$ e chegam aos $50,8 \%$ de municipalização. Os dados indicam continuidade do processo iniciado pelo FUNDEF, que reorganizou a oferta educacional dessa etapa de ensino entre as redes estadual e municipal. No entanto, esse processo ocorreu de maneira diferenciada entre regiões e Unidades da Federação. 
A oferta do Ensino Fundamental no contexto do FUNDEB

As regiões com maior percentual de municipalização nos anos iniciais e finais do Ensino Fundamental, entre 2007 e 2019, foram Nordeste e Norte, que alcançaram, no último ano, o percentual de $96,7 \%$ e $84,8 \%$, respectivamente. Nos anos finais também são as duas regiões mais municipalizadas, chegando a 2019 com 81,2\% (Nordeste) e 52,1\% (Norte). Por outro lado, a região que apresenta menor taxa de municipalização é a Centro-Oeste, nos anos iniciais $(71,8 \%)$ e finais $(27,6 \%)$ do Ensino Fundamental.

Nas Unidades da Federação o processo de municipalização continuou crescente, alcançando, no Rio de Janeiro, Bahia, Paraná, Ceará e Piauí, quase a totalidade das matrículas (mais de 99\%) nos anos iniciais do Ensino Fundamental. Os menores percentuais de municipalização dessa etapa foram no Acre $(57,2 \%)$, Rio Grande do Sul $(63 \%)$ e Amapá (65,3\%). De 2007 para 2019, os maiores percentuais de crescimento da municipalização foram em Tocantins, que saiu de $60,7 \%$ e alcançou $90,2 \%$, e em Roraima, que passou de $37,8 \%$ para $84,9 \%$ no período. O maior percentual de municipalização no Rio de Janeiro $(99,8 \%)$, em 2019 , foge à tendência de municipalização nos estados nordestinos.

No que se refere aos anos finais do Ensino Fundamental, diferentemente dos anos iniciais, que tiveram crescimento em todas as Unidades da Federação, se observa quedas em oito estados, sendo mais significativa em Rondônia, onde a taxa de municipalização caiu de $33 \%$ para $15,3 \%$. Os maiores percentuais de municipalização dos anos finais, em 2019, foram verificados em estados nordestinos, sendo maior no Ceará (96,6\%), Maranhão (95,2\%), Bahia $(82,3 \%)$ e Piauí $(81,1 \%)$. Os menores no Paraná $(1,5 \%)$, Roraima $(2,2 \%)$ e Amapá $(4 \%)$. Os Estados que mais cresceram percentualmente na taxa de municipalização foram Pernambuco, Bahia e Ceará. Os dados indicam que foi se estabelecendo em alguns estados a cultura de dividir a responsabilidade da oferta pelo Ensino Fundamental, ficando os anos iniciais com as redes municipais e, os finais, com as redes estaduais, como percebido no Paraná e em Roraima. Embora em menor disparidade, os anos finais em Mato Grosso, São Paulo, Goiás, Tocantins, Acre, Rondônia, Amapá também apresentam a tendência de estadualização.

\section{Considerações finais}

A instituição da política de fundos no Brasil reorganizou o padrão de oferta das diferentes etapas e modalidades de ensino entre as redes municipais e estaduais de educação, implicando a reorganização das relações federativas na oferta da educação obrigatória, decorrente do seu sistema de captação e redistribuição de recursos no interior dos estados e da complementação da União.

$\mathrm{Na}$ intenção de analisar o impacto do FUNDEB na oferta do Ensino Fundamental no Brasil, foram sistematizadas a evolução das matrículas, as taxas de atendimento escolar e de matrícula bruta e líquida e a participação de estados e municípios das diferentes regiões e Unidades da Federação na oferta dessa etapa de ensino, de 2007 a 2019, com base nos dados educacionais do INEP e do IBGE. Pretendeu-se verificar as características da oferta no contexto do FUNDEB, decorrente do avanço na universalização do Ensino Fundamental e da inclusão das demais etapas e modalidades da Educação Básica na matriz de financiamento da educação mediante Fundos.

No contexto do FUNDEF, embora tenha ocorrido a reorganização da oferta do Ensino Fundamental entre as redes, foi constatado que, de 1996 para 2006, houve um crescimento 
A oferta do Ensino Fundamental no contexto do FUNDEB

de apenas 1,4\% nas matrículas estaduais e municipais do Ensino Fundamental no Brasil. No caso do FUNDEB, houve um movimento descendente na oferta, indicando queda de $24 \%$ nas matrículas entre os anos de 2007 a 2019, movimento presente em todas as regiões do País, sendo mais intensa no Nordeste (31\%) e no Sul (22\%) e Sudeste (23\%). Apenas Roraima e Acre tiveram aumento da oferta. As quedas mais significativas, de $26 \%$ a $37 \%$, foram nos estados nordestinos, cuja maioria recebeu a complementação da União durante o FUNDEB. Queda significativa também foi observada no Sul e Sudeste, variando de $26 \%$ a $30 \%$.

O movimento descendente das matrículas do Ensino Fundamental foi considerado intrigante na investigação, levando à hipótese de que se justificaria pela universalização dessa etapa da Educação Básica. No entanto, o FUNDEF não alcançou a universalização, deixando um saldo $94,8 \%$ de taxa de escolarização líquida e $97,6 \%$ de escolarização bruta. Por si só o esforço para universalizar justificaria o aumento das matrículas, o que não aconteceu. Houve queda de matrículas concomitante com o aumento das taxas de atendimento escolar e de matrícula bruta e líquida.

A taxa de atendimento escolar teve aumento constante de 2007 a 2015, embora não tenha alcançado a totalidade da população de seis a 10 anos $(99,2 \%)$ e de 11 a 14 anos $(97,7 \%)$. No mesmo período, a taxa de matrícula bruta aumentou nos anos iniciais do Ensino Fundamental e caiu nos anos finais, alcançando $105 \%$ e $94,7 \%$, respectivamente. A taxa de matrícula líquida também teve crescimento no período, chegando a $92,72 \%$ nos anos iniciais e $77,52 \%$ nos anos finais. Os dados revelam que existe potencial significativo de crescimento das matrículas nos anos iniciais e finais do Ensino Fundamental, principalmente nas regiões em que houve maior queda durante a vigência do FUNDEB. O Nordeste alcançou apenas $86,5 \%$ nos anos iniciais e $69,1 \%$ nos finais. O Norte, $93 \%$ e $72,3 \%$, no mesmo período.

No que se refere à distribuição das matrículas do Ensino Fundamental, buscou-se analisar se a municipalização, constatada durante a vigência do FUNDEF (1996-2006), permaneceu durante o FUNDEB (2007-2019). Com o primeiro Fundo alcançou-se $60 \%$ de municipalização em 2006. Com o FUNDEB houve continuidade desse processo, chegando a $69 \%$ em 2019, sendo mais acentuado nos anos iniciais do Ensino Fundamental, pois saiu de $75,9 \%$, em 2007 , e alcançou $83,7 \%$, em 2019 . No mesmo período, os anos finais saíram dos $42 \%$ e chegam aos $50,8 \%$ de municipalização. As regiões com maior percentual de municipalização nos anos iniciais, em 2019 , foram Nordeste $(96,7 \%)$ e Norte $(84,8 \%)$, situação que se reiterou nos anos finais, com $81,2 \%$ e $52,1 \%$, respectivamente.

O saldo do FUNDEB, no aspecto da oferta do Ensino Fundamental, é de que a municipalização está consolidada nos anos iniciais porque a menor taxa foi de $57 \%$ (Acre) e a maior (acima de 99\%) alcançou o Rio de Janeiro, Bahia, Paraná, Ceará e Piauí. Nos anos finais houve crescimento significativo, de 2007 para 2019, na taxa de municipalização, principalmente em estados nordestinos, embora nove estados do Brasil tenham mudado de rota e decrescido na oferta municipal, configurando a estadualização dessa etapa do Ensino Fundamental (Paraná, Roraima, Mato Grosso, São Paulo, Goiás, Tocantins, Acre, Rondônia, Amapá).

A hipótese inicial era de que a inclusão das demais etapas e modalidades no FUNDEB levaria à reorganização da oferta mediante ampliação dessas matrículas, o que poderia afetar, também, o Ensino Fundamental, que, como explicitado, teve queda de $24 \%$. No entanto, contraditoriamente, se no FUNDEF, de 1996 para 2006, houve aumento das matrículas da 
A oferta do Ensino Fundamental no contexto do FUNDEB

pré-escola $(27,7 \%)$ e do Ensino Médio (74,6\%), no FUNDEB, de 2007 para 2019, houve crescimento considerável na creche $(133 \%)$, moderado na pré-escola $(2 \%)$ e queda no Ensino Médio (15\%) e na EJA (37\%), frustrando as expectativas de que o novo Fundo seria mais inclusivo ao viabilizar o direito à educação para todas as etapas e modalidades do ensino obrigatório no Brasil, o que ocorreu somente na etapa com a menor taxa de atendimento, a Educação Infantil.

\section{Referências}

ABRÚCIO, Fernando Luís. Coordenação Federativa no Brasil: uma experiência do período FHC e os desafios do governo Lula. Revista de Sociologia e Política, Curitiba, n. 24, p. 4167, jun. 2005. Dossiê Federalismo.

ALVES, Thiago; SILVEIRA, Adriana A. Dragone; SCHNEIDER, Gabriela. Financiamento da Educação Básica: o grande desafio para os municípios. Revista Retratos da Escola, Brasília, v. 13, n. 26, p. 391-413, maio/ago. 2019.

AMARAL, Nelson Cardoso. O Fundeb em uma perspectiva comparada com o financiamento da educação básica nos países da OCDE e do BRICS. Em Aberto, v. 28, n. 93, p. 67-84, jan./jun. 2015.

ARAÚJO, Raimundo Luiz Silva. Limites e possibilidades da redução das desigualdades territoriais por meio do financiamento da educação básica. 2014. Tese (Doutorado em Educação) - Faculdade de Educação, Universidade de São Paulo, São Paulo, 2014.

ARELARO, Lisete; JACOMINI, Márcia; KLEIN, Sylvie. B. O ensino fundamental de nove anos e o direito à educação. Educação e Pesquisa, São Paulo, v. 37, n. 1, p. 35-51, jan./abr. 2011. Disponível em: <https://www.scielo.br/pdf/ep/v37n1/v37n1a03.pdf>. Acesso em: 17 maio 2020.

BANCO MUNDIAL. Relatório n. 24.413 - BR. Educação Municipal no Brasil - Recursos, Incentivos e Resultados. Relatório de Políticas. v. 120 p. v. 2113 p. Brasil: Banco Mundial, 2003.

BARRETO, Elba Siqueira de Sá; ARELARO, Lisete Regina Gomes. A municipalização do ensino de $1^{\circ}$ grau: tese controvertida. Revista da Faculdade de Educação, São Paulo, n. 11, p. 193-210, jan./dez. 1985. Disponível em: <http://www.revistas.usp.br/rfe/article/view/ 33344/36082>. Acesso em: 6 jul. 2020.

BASSI, Marcos; FERNANDES, Maria Dilnéia Espíndola; ROLIM, Rosana Maria Gemaque (Org.). Remuneração de Professores da Educação Básica das Redes Municipais de Ensino no Contexto do FUNDEB e do PSPN. Paraná: Appris, 2018.

BRAGA, Marcus Vinicius de Azevedo. Conselhos do FUNDEB: participação e fiscalização no controle social da educação. Curitiba: Editora Appris, 2015.

BRASIL. Lei $n^{\circ}$ 5.692, de 11 de agosto de 1971. Fixa Diretrizes e Bases para o ensino de $1^{\circ}$ e $2^{\circ}$ graus, e dá outras providências. Diário Oficial da União, Brasília, 1971. Disponível em: <http://www.planalto.gov.br/ccivil_03/leis/l5692.htm>. Acesso em: 30 abr. 2020. 
A oferta do Ensino Fundamental no contexto do FUNDEB

BRASIL. Constituição da República Federativa do Brasil. Promulgada em 5 de outubro de 1988. Diário Oficial da União, Brasília, 1988. Disponível em: <http://www.planalto. gov.br/ccivil_03/Constituicao/Constituicao.htm>. Acesso em: 10 fev. 2017.

BRASIL. Emenda Constitucional $n^{\circ} 14$, de 12 de setembro de 1996. Modifica os artigos 34 , 208, 211 e 212 da Constituição Federal e da nova redação ao artigo 60 do ato das disposições constitucionais transitórias. Diário Oficial da União, Brasília, 1996a. Disponível em: < http://www.planalto.gov.br/ccivil_03/constituicao/emendas/emc/emc14.htm>. Acesso em: 10 jul. 2019.

BRASIL. Lei Complementar $n^{\circ} 87$, de 13 de setembro de 1996. Dispõe sobre o imposto dos Estados e do Distrito Federal sobre operações relativas à circulação de mercadorias e sobre prestações de serviços de transporte interestadual e intermunicipal e de comunicação, e dá outras providências. (LEI KANDIR). Diário Oficial da União, Brasília, 1996b. Disponível em: <http://www.planalto.gov.br/ccivil_03/leis/lcp/lcp87.htm>. Acesso em: 6 jul. 2020.

BRASIL. Lei $n^{\circ}$ 9.394, de 20 de dezembro de 1996. Estabelece as diretrizes e bases da educação nacional. Diário Oficial da União, Brasília, 1996c. Disponível em: <http://www.planalto.gov.br/ccivil_03/leis/l9394.htm>. Acesso em: 30 abr. 2020.

BRASIL. Lei no 9.424, de 24 de dezembro de 1996. Dispõe sobre o Fundo de Manutenção e Desenvolvimento do Ensino Fundamental e de Valorização do Magistério, na forma prevista no art. $60, \S 7^{\circ}$, do Ato das Disposições Constitucionais Transitórias, e dá outras providências. Diário Oficial da União, Brasília, 1996d. Disponível em: <http://www.planalto.gov .br/ccivil_03/LEIS/L9424.htm>. Acesso em: 15 nov. 2019.

BRASIL. Lei n 10.172, de 09 de janeiro de 2001. Aprova o Plano Nacional de Educação e dá outras providências. Diário Oficial da União, Brasília, 2001. Disponível em: <http://www.planalto.gov.br/ccivil_03/leis/leis_2001//10172.htm>. Acesso em: 04 abr. 2020.

BRASIL. Lei $n^{\circ} 11.114$, de 16 de maio de 2005 . Altera os arts. $6^{\circ}, 30,32$ e 87 da Lei $n^{\circ} 9.394$, de 20 de dezembro de 1996, com o objetivo de tornar obrigatório o início do ensino fundamental aos seis anos de idade. Diário Oficial da União, Brasília, 2005. Disponível em: <http://www.planalto.gov.br/ccivil_03/_Ato2004-2006/2005/Lei/L11114.htm\#art1>. Acesso em: 30 abr. 2020.

BRASIL. Lei $n^{\circ} 11.274$, de 6 de fevereiro de 2006. Altera a redação dos arts. 29, 30, 32 e 87 da Lei $\mathrm{n}^{\circ}$ 9.394, de 20 de dezembro de 1996, que estabelece as diretrizes e bases da educação nacional, dispondo sobre a duração de 9 (nove) anos para o ensino fundamental, com matrícula obrigatória a partir dos 6 (seis) anos de idade. Diário Oficial da União, Brasília, 2006a. Disponível em: <http://www.planalto.gov.br/ccivil_03/leis/19394.htm>. Acesso em: 30 abr. 2020.

BRASIL. Emenda Constitucional $n^{\circ} 53$, de 19 de dezembro de 2006. Dá nova redação aos artigos $7^{\circ}, 23,30,2006,208,211$ e 212 da Constituição Federal e ao artigo 60 do Ato das Disposições Constitucionais Transitórias. Diário Oficial da União, Brasília, 2006b. Disponível em: <http://www.planalto.gov.br/ccivil_03/constituicao/Emendas/Emc/emc53.htm>. Acesso em: 17 maio 2020. 
A oferta do Ensino Fundamental no contexto do FUNDEB

BRASIL. Lei $n^{\circ} 11.494$, de 20 de junho de 2007. Regulamenta o Fundo de Manutenção e Desenvolvimento da Educação Básica e de Valorização dos Profissionais da Educação FUNDEB, de que trata o art. 60 do Ato das Disposições Constitucionais Transitórias; altera a Lei $n^{\circ} 10.195$, de 14 de fevereiro de 2001; revoga dispositivos das Leis $n^{\circ s} 9.424$, de 24 de dezembro de 1996, 10.880, de 9 de junho de 2004, e 10.845, de 5 de março de 2004; e dá outras providências. Diário Oficial da União, Brasília, 2007. Disponível em: <http://www.planalto.gov.br/ccivil_03/_ato2007-2010/2007/lei//11494.htm>. Acesso em: 30 abr. 2020.

BRASIL. Emenda Constitucional $n^{\circ} 59$, de 11 de novembro de 2009. Diário Oficial da União, Brasília, 2009. Disponível em: <http://www.planalto.gov.br/ccivil_03/constituicao/emendas lemc/emc59.htm>. Acesso em: 15 set. 2018.

CAMARGO, Rubens Barbosa de; JACOMINI, Márcia Aparecida. Remuneração de professores de escolas públicas no contexto do FUNDEF. In: GOUVEIA, Andrea Barbosa; PINTO, José Marcelino de Rezende; FERNANDES, Maria Dilnéia Espíndola (Org.). Financiamento da Educação no Brasil: os desafios de gastar 10\% do PIB em dez anos. Campo Grande: Ed. Oeste, 2015. p. 225-256.

CASTRO, Jorge Abrahão de; DUARTE, Bruno de Carvalho. Descentralização da Educação pública no Brasil: evolução dos gastos e matrículas. 2007. 25 f. Disponível em: $<$ http://www.anped.org.br/sites/default/files/trabalho_encomendado_gt05_-_int.pdf $>$. Acesso em: 15 fev. 2020.

DAVIES, Nicholas. O FUNDEF e as verbas da educação. São Paulo: Xamã, 2001.

DAVIES, Nicholas. Controle estatal ou social das verbas da educação? In: PINTO, José Marcelino de Rezende; SOUZA, Silvana Aparecida de (Org.). Para onde vai o dinheiro? Caminhos e descaminhos do financiamento da educação. São Paulo: Xamã, 2014. p. 133146.

IBGE. Instituto Brasileiro de Geografia e Estatística. Censo Demográfico - 2000, 2010. População por faixa etária. Rio de Janeiro, 2010. Disponível em: <https://sidra. ibge.gov.br/pesquisa/censo-demografico>. Acesso em: 12 maio 2020.

IBGE. Instituto Brasileiro de Geografia e Estatística. Pesquisa Nacional por Amostra de Domicílios Contínua. 2018. População por faixa etária. Rio de Janeiro, 2018. Disponível em: <https://sidra.ibge.gov.br/pesquisa/pnad>. Acesso em: 12 maio 2020.

IBGE. Instituto Brasileiro de Geografia e Estatística. Taxa de Escolarização - Grupo de idade: estudantes (7 a 14 anos) em 2006. Rio de Janeiro, 2006. Disponível em: $<$ https://brasilemsintese.ibge.gov.br/educacao/taxa-de-escolarizacao-das-pessoas-de-6-a14-anos.html>. Acesso em: 12 maio 2020.

INEP. Instituto Nacional de Estudos e Pesquisas Educacionais Anísio Teixeira. Relatório do $2^{\circ}$ ciclo de monitoramento das metas do Plano Nacional de Educação 2018. 2. ed. Brasília: Inep/Mec, 2019. Disponível em: <http://portal.inep.gov.br/informacao-da-publicacao/lasset_publisher/6JYIsGMAMkW1/document/id/6725829>. Acesso em: 26 maio 2020.

INEP. Instituto Nacional de Estudos e Pesquisas Educacionais Anísio Teixeira. Relatório do $3^{\circ}$ ciclo de monitoramento das metas do Plano Nacional de Educação 2020. Brasília: 
A oferta do Ensino Fundamental no contexto do FUNDEB

Inep/Mec, 2020a. Disponível em: <http://portal.inep.gov.br/informacao-da-publicacao/lasset_publisher/6JYIsGMAMkW1/document/id/6935276>. Acesso em: 12 jul. 2020.

INEP. Instituto Nacional de Estudos e Pesquisas Educacionais Anísio Teixeira. Microdados do Censo Escolar - 1996, 2006, 2007, 2013 e 2019. Brasília, 2020b. Disponível em: <http://inep.gov.br/microdados>. Acesso em: 12 maio 2020.

LOYOLA, Paulo. Autonomia municipal e interdependência federativa: uma análise sobre as mudanças ocorridas no acesso e nos gastos em educação no Brasil (2000 - 2014). Educação e Sociedade, Campinas, v. 38, n. 140, p. 767-790, jul. 2017.

MARTINS, Paulo de Sena. FUNDEB, Federalismo e Regime de Colaboração. Campinas: Autores Associados, 2011.

MILITÃO, Silvio Cesar Nunes. O FUNDEB e a municipalização do ensino fundamental em São Paulo: novo fundo, velhas tendências. Educação: Teoria e Prática, Rio Claro, v. 22, n. 41, set./dez. 2012.

MONLEVADE, João; FERREIRA, Eduardo. O FUNDEF e seus pecados capitais. Ceilândia: Idéa, 1998.

NASCIMENTO, Iracema Santos (Org.). Fundeb pra Valer! A incidência política da Campanha Nacional pelo Direito à Educação na criação do Fundo da Educação Básica. São Paulo: Chiado, 2019.

PINTO, José Marcelino de Rezende. Um fundinho chamado "Fundão". In: DOURADO, Luiz Fernandes (Org.). Financiamento da Educação Básica. Campinas: Editora Autores Associados; Goiânia: Editora da UFG, 1999. p. 86-98.

PINTO, José Marcelino de Rezende. A política recente de fundos para o financiamento da educação e seus efeitos no pacto federativo. Educação \& Sociedade, Campinas, v. 28, n. 100 , p. 877-897, out. 2007.

PINTO, José Marcelino de Rezende. Financiamento da educação básica. A divisão de responsabilidades. Retratos da Escola, Brasília, v.6, n. 10, p. 155-172, jan./jun. 2012.

PINTO, José Marcelino de Rezende. O financiamento da educação na constituição federal de 1988: 30 anos de mobilização social. Educação \& Sociedade, Campinas, v. 39, n. 145, p. 846-869, dez. 2018.

PINTO, José Marcelino de Rezende; ALVES, Thiago. O impacto financeiro da ampliação da obrigatoriedade escolar no contexto do Fundeb. Educação \& Realidade, Porto Alegre, v. 36, n. 2, p. 605-624, maio/ago. 2011.

PRADO, Sérgio (Org.). Partilha de recursos na Federação Brasileira. São Paulo: Fundap/Fapesp/IPEA, 2003. (Coleção Federalismo no Brasil).

UFPR. Universidade Federal do Paraná. Laboratório de Dados Educacionais. Número de matrículas - 2007, 2013, 2019. Curitiba, 2020. Disponível em: <https://dadoseducacio nais.c3sl.ufpr.br/\#/indicadores/matriculas>. Acesso em: 12 maio 2020. 
A oferta do Ensino Fundamental no contexto do FUNDEB

UFPR. Universidade Federal do Paraná. Laboratório de Dados Educacionais. Taxa de atendimento escolar - 2007, 2013, 2015. Curitiba, 2016a. Disponível em: <https://dadose ducacionais.c3sl.ufpr.br/\#/indicadores/atendimento>. Acesso em: 12 maio 2020.

UFPR. Universidade Federal do Paraná. Laboratório de Dados Educacionais. Taxa de matrícula líquida - 2007, 2013, 2015. Curitiba, 2016b. Disponível em: <https://dadosedu cacionais.c3sl.ufpr.br/\#/indicadores/matricula-liquida>. Acesso em: 12 maio 2020.

UFPR. Universidade Federal do Paraná. Laboratório de Dados Educacionais. Taxa de matrícula bruta - 2007, 2013, 2015. Curitiba, 2016c. Disponível em: <https://dadoseduca cionais.c3sl.ufpr.br/\#/indicadores/matricula-bruta>. Acesso em: 12 maio 2020.

UFPR. Universidade Federal do Paraná. Laboratório de Dados Educacionais. População fora da escola - 2007, 2015. Curitiba, 2016d. Disponível em: <https://dadoseduca cionais.c3sl.ufpr.br/\#/indicadores/populacao-fora-escola>. Acesso em: 12 maio 2020.

Rosana Evangelista da Cruz é docente no Programa de Pós-Gradução em Educação, vinculada ao Departamento de Fundamentos da Educação, membro do Núcleo de Estudos e Pesquisas em Políticas e Gestão da Educação.

ORCID: http://orcid.org/0000-0002-8341-0835

E-mail: rosanacruz@ufpi.edu.br

Aline Kazuko Sonobe é doutora em Educação pela Universidade Federal do Paraná, vinculada ao Núcleo de Pesquisa em Políticas Educacionais.

ORCID: http://orcid.org/0000-0002-3416-2863

E-mail: kazuko.as@gmail.com

Recebido em 31 de maio de 2020

Aprovado em 13 de julho de 2020 


\section{Editores do volume 10}

Márcia Aparecida Jacomini - Universidade Federal de São Paulo, Brasil

José Marcelino de Rezende Pinto - Universidade de São Paulo, Brasil

\section{Comitê Editorial}

Nalú Farenzena - Universidade Federal do Rio Grande do Sul, Brasil

Juca Gil - Universidade Federal do Rio Grande do Sul, Brasil

Theresa Adrião - Universidade Estadual de Campinas, Brasil

Ângelo Ricardo de Souza - Universidade Federal do Paraná, Brasil

\section{Conselho Editorial}

\section{Alejandro Morduchowicz}

Universidad Pedagógica, Provincia de Buenos Aires, Argentina

Andréa Barbosa Gouveia

Universidade Federal do Paraná, Brasil

Fernanda Saforcada

Universidade de Buenos Aires, Argentina

Jacques Velloso

Universidade de Brasília, Brasil

João Monlevade

Senado Federal, Brasil

Jorge Abrahão de Castro

Instituto de Pesquisa Econômica Aplicada / IPEA, Brasil

Lisete Regina Gomes Arelaro

Universidade de São Paulo, Brasil

Luis Carlos Sales

Universidade Federal do Piauí, Brasil

Luiz de Sousa Junior

Universidade Federal da Paraíba, Brasil

Luiz Fernandes Dourado

Universidade Federal de Goiás, Brasil

Magna França

Universidade Federal do Rio Grande do Norte, Brasil

Marcos Edgar Bassi

Universidade Federal de Santa Catarina, Brasil

Maria Angélica Pedra Minhoto

Universidade Federal de São Paulo, Brasil

Maria Beatriz Luce

Universidade Federal do Rio Grande do Sul, Brasil

Maria Dilnéia Espíndola Fernandes

Universidade Federal de Mato Grosso do Sul, Brasil

Nelson Cardoso do Amaral

Universidade Federal de Goiás, Brasil

Nicholas Davies

Universidade Federal Fluminense, Brasil

Robert E. Verhine

Universidade Federal da Bahia, Brasil

Romualdo Portela de Oliveira

Universidade de São Paulo, Brasil

Rosana Gemaque Rolim

Universidade Federal do Pará, Brasil

Rubens Barbosa de Camargo

Universidade de São Paulo, Brasil

Theresa Adrião

Universidade Estadual de Campinas, Brasil

Tristan McCowan

University of London, Reino Unido

Vera Jacob

Universidade Federal do Pará, Brasil

Vera Peroni

Universidade Federal do Rio Grande do Sul, Brasil

Vitor Henrique Paro

Universidade de São Paulo, Brasil

\section{Equipe editorial}

Apoio ao Comitê Editorial: Caio Cabral da Silva

Diagramação, Revisão de português e normalização: Edson Leonel de Oliveira

Revisão de inglês: Sabrina Ferreira

Fineduca - Revista de Financiamento da Educação

Associação Nacional de Pesquisa em

Financiamento da Educação

e-mail: revista.fineduca@gmail.com | site: http://seer.ufrgs.br/fineduca 